\title{
Quality management technology impact on small enterprise production activities
}

\author{
Natalia Ivanova ${ }^{1, *}$, Zoya Lavrova $^{2}$ \\ ${ }^{1}$ Peter the Great St. Petersburg Polytechnic University, 195251, Saint-Petersburg, Russia \\ ${ }^{2}$ St. Petersburg State Economics University, 191023, Saint-Petersburg, Russia
}

\begin{abstract}
A modern quality management technology, the so-called quality management system (QMS), can improve the indicators of production activities of any company. Due to the advantages of a small business such project can be implemented faster and at lesser costs. The conducted research of the QMS development in accordance with ISO 9001-2015 at a particular small St. Petersburg enterprise in 2016 resulted in the growth of production output and labor productivity. The obtained results of the standards introduction in the troublesome divisions of a small firm demonstrate the attractiveness of the given technology for the top management of a corporation.
\end{abstract}

\section{Introduction}

Enterprises and their types of business associations (firms, companies, corporations, trusts, syndicates, etc.) are a product of the industrial age. Due to realizing of unifying processes under the rapid development of information technologies in the late twentieth century they have been turned into the international network structures [1]. As a result, created a need in the management of them, which led to the creation of a scientific management theory, the main object of which became a large organization. It is known for such companies was typical a mechanistic / bureaucratic type of management (on vertical). This was facilitated by the emergence of management technologies related to various functional managerial spheres of associations, among them strategic, innovative, financial, industrial, environmental, international management, quality management, human resources, organizational behavior and so on) [2].

Particular importance belongs to technologies of quality management, directly related to safety of manufactured products or services for a person and his environment [3]. Among them there are the control charts Shewhart V., G. Gantt chart, seven quality control tools, Six Sigma, etc. In a greater degree they were directed at the quality control of the production process, and in 1951 A. Feigenbaum embodied them in the concept of total quality control (TQC) [4, pp. 11-17]. The importance of quality management technologies is confirmed by the data: marketing researches show, that the selection this or that production on $75 \%$ determines its quality [5].

Gradually mechanistic management style was replaced on a more flexible organic (on horizontal) under the influence information technologies in conditions of uncertainty of factors of external environment postindustrial era [6]. This was made possible in the framework of quality management technology, which called a quality management system (QMS). It allows to work out accurately documented procedures (business processes), included in the production process on base of international standards ISO 9000 and under influence of total quality management concept (TQM).

It is considered in the existing practice of international business the development and implementation of a certified quality management system at the enterprise testifies to the high quality of manufactured products (services), forms the confidence of consumers and strengthens the earned image on occupied market segments [7]. So, a certified quality management system of $87-90 \%$ of the firms confirms their high level of competitiveness, while at $73 \%$ of companies - ensures their a stable financial indicators [8].

\section{Formulation of the problem}

The quality problem is actual in any historical period. For example, in the industrial age initially manufacturer himself had to solve this problem both in the conditions of becoming production and growing production volume, that inevitably accompanied by a lot of marriage. The manufacturer was directly interested in the quality, because he exercised a choice of production and defined the technical requirements for it. The result of the unifying processes realization at the enterprise and of implementation of information technologies in the postindustrial era became the variety of goods and services

*Corresponding author: ing4@bk.ru

(C) The Authors, published by EDP Sciences. This is an open access article distributed under the terms of the Creative Commons Attribution License 4.0 (http://creativecommons.org/licenses/by/4.0/). 
offered by a huge number of different manufacturers who are forced for the conquest the market take into account the requirements of consumers to quality of products / services in terms of safety for human use [3].

Hence, goals of an international standardization and certification are understandable in the conditions of globalization and aim at the development international trade and scientific and technical exchange between countries, that expressed in the creation of international standards ISO 9000. According to data of the international organization ISO [9], more than one million certificates of conformity to ISO 9001 were given out worldwide.

In the scientific literature extensively discusses the creation of a quality management system (QMS) in various enterprises. International quality management practice considers the approaches related to Integrating Lean Six Sigma with ISO 9001-2015 [10] and ISO based on TQM implementation approach as major management approaches, used in foreign companies [11, 12]. At the same time these enterprises are interested in economic and social effectiveness of certification on the ISO 9000, including external customer satisfaction and internal customer satisfaction, which are assessed there [13, 14].

Russian scientists study and use positive international experience in quality management. In particular, in Russia is known method of the German specialist Stefan Hensch, implemented in the company "Hensch development of quality" on the base of process approach and project approach [15].

A number of Russian experts, noting the impact of the quality management system on the success of the company, points to the formal conducting of this project on its development and implementation [16-18]. Often getting the certificate of conformity, which gives the company a competitive advantages, such as when participating in tenders, receipt of benefits in lending and insurance, etc., is not accompanied by the reorganization of the production activities on quality assurance. This is confirmed by the results of the poll workers about the reasons for the ineffectiveness of the quality management system: $73 \%$ - lack of training on QMS, $67 \%$ - lack of interest of leadership, $63 \%$ - lack of quality department and of qualified specialists in quality management, $45 \%$ - lack of interest and of involvement of staff, $43 \%$ - insufficient allocation of funds and the lack of systematic accounting the quality costs [19]. Dominant leadership role in resolving quality issues is obvious, on which falls of wine in the amount of 80 $85 \%$, and only $15-20 \%$ depends on the direct perpetrators [20].

In the articles in addition to these disadvantages the positive results of the QMS functioning at the enterprise are presented. During the period 2013-2015 at the EastSiberian railway ("RZD" branch) marked increase in indicators: labor productivity - by $4 \%$, passenger turnover - by $0.6 \%$; customer satisfaction - by $0.7 \%$ [21].

In general, in Russia the situation with the development and implementation of the QMS is improved, it confirms the change in the index of global competitiveness of the Russian Federation: it moved from 53th to 45th place ( 8 positions) in 2016 compared to 2015 and 45 th at the 43 th place (another 2 positions) in 2017 compared to 2016 [22, 23].

This is especially true of small businesses whose leaders are busy with not only the execution of strategic functions, but of operating functions a greater extent than in large companies, where they have the functional deputies.

At the same time to small businesses, who organize QMS certification, there are the following characteristics:

1) small, skilled and cohesive team;

2) a wide range of tasks undertaken by each employee;

3) simple and direct communication between employees;

4) limitation in the decision-making (till one person);

5) flexibility, real customer focus;

6) often lack of documentation;

7) limited financial resources [24].

These characteristics together with the smaller scale of the activity of small enterprises offer great opportunities for the introduction of the QMS and reduce the duration of the project stages for its improvement.

Therefore, by the object of the work is selected the small production enterprise (by the example of LLC "ZETA "CONTACT"). Its director has realized the importance of resolving quality problem using QMS implementation technology (practical significance).

Scientific novelty of the research is contained in the planning for the implementation of QMS in large companies like in a small enterprise, starting with the problematic divisions, gradually expanding the coverage of the QMS of all large processes that describe activities of the company. In this case it's enough only one qualified person who studies the specifics of departments, services during a shorter workweek. Thus, the cost of implementing QMS will be minimized, and the quality management system itself will become more attractive for the top-management of large companies.

\section{The evolution in the field of Quality Management}

In the scientific theory of quality management most often there are 5 stages of quality evolution, accompanied by the standards improvement process.

1. Focus of manufacturer on finished product quality, which aimed at the defective goods rejection by inspection based on the methodology of statistical quality control (SQC) in the earlier period of production (until the 1950s.).

2. Increased attention of manufacturer to the product designing quality and the manufacturing process quality due to the wide implementation of A. Feigenbaum total quality control concept (TQC) (1950-1960s.).

3. Studying of customer needs and suppliers' products quality in conditions of tightening market competition in the 1960-1970s.

4. Inclusion in quality products concept not only quality of its designing and production process, but also 
its after-sales service quality, spreading the "quality assurance system" concept (1980-1990s.).

5. The direction of manufacturer's efforts on the errors prevention as a result of intensive development of total quality management (TQM) a new concept, focused on the consumer. Quality management covers all the enterprise activities (1990-2000s.) [4].

At present in the emerging global society is appropriate to speak about the beginning of the sixth stage of the evolution of quality (since 2000), associated with the increasing role of human knowledge in economics and management. It is recognized, knowledge of people creates ideas, forms a team, which their realizes and helps to transform them into innovation. Already now modern technology are beginning to rule the whole world. In this situation the quality acquires a universal character, embodied in types of a public security [3] on the supranational level of cooperation between different countries. This is reflected in international standardization. The evolution of it in compliance with ISO 9000 is considered below.

In 1987 a series of international standards ISO 9000, based on standards of the British Standard Institution (BSI 5750), was developed. It appeared as a response to the globalization of the economy. At the same time, the first edition of standards has not covered a number of specific types of products, including software and services.

In 1994 the technical committee ISO (ISO / TC 176) revised the first edition of standards based on their application experience in different business areas of different countries and on approved recommendations of the national certification bodies. As a result, three standard models appeared: for quality assurance in designing, development, production, installation and servicing (ISO 9001-1994); for quality assurance in production, installation and servicing (ISO 9002-1994); for quality assurance in finished products control and testing (ISO 9003-1994). This is forced the companies to undergo the certification procedure once again while expansion or contraction of business scope took place. In spite of the specified disadvantage of three standards, here has been declared the process approach and became to use the concept of "preventive action" to prevent a potential non-compliance of requirements.

The impact of total quality management concept (TQM) is reflected in the third edition of ISO 9001-2000 "Quality Management System. Requirements", where a universal model for all organizations, size, industry, product or service regardless, has been established. It is based on the concept of industrial business processes: a lot of attention paid to the functioning and controlling processes according to the changes in consumer satisfaction and strivings to continued improvement.

The universality of QMS, developed in 2000, is confirmed by the fact that the fourth edition of standards ISO 9001-2008 [25] offered no significant changes. They concerned the clear understanding of certain requirements, also the definitions of some terms were clarified and simplified. In both versions the accent was made on managers forces transfer from identifying and eliminating inconsistencies to the preventing their occurrence, eliminating or minimizing the possibility of their occurrence during the process of product creation or services and throughout the whole product lifecycle [26]. This led to the appearance of a well-known rule: "tenfold costs increase on the defect elimination by its detection on the next stage of the lifecycle, not on given one" [27]. Thus, corrective actions become nearly the most important in quality management system (QMS). Without managing costs using quality calculating methods, constant increase of products (works, services) quality requirements may cause the increase of costs on its providing [28, pp. 23-43]. Then it is appropriate to speak about the economic and social efficiency of QMS in the context of conformity of intended results and purpose and degree of its achievement taking into account the costs.

Further development of the information society has caused appearance of the fifth standards edition ISO 9001-2015 [29]. It cardinally reviewed QMS created in company, which means its personal choice independence not only in the term of volume but also in term of the documented procedures content [30]. The benefits of companies with implemented certified quality management system are:

- management efforts concentration on the organization risks and opportunities caused by external and internal organization environment, connected with the appearance of such thing as a "risk-oriented thinking" in the text of ISO 9001-2015;

- creation of documented and undocumented information complex, related to organization knowledge (procedures, instructions, regulations, training techniques and other personnel competence, formed during its time of work in a particular company).

Thereby, the new version of ISO 9001-2015 is much more oriented to the management improvement, depended on senior management and the workers themselves. Only the top-manager, who is endowed with the responsibility for quality, can show by his own example and explain the workers with specific competencies the loyalty to the implemented quality management system of the company.

\section{QMS introduction results at the small enterprise}

As mentioned, the last revision of the international standard ISO 9001-2015 became the most serious of its revision since 2000. First of all, freedom is impressive, which is received by the companies in choosing the means of standard requirements implementation, that is especially valuable for small business organization. Considering that the company practically lacks specific human resources, it is possible to minimize the documentation of carried out activity if this is not necessary. Standard is focused not on reproduction of paper or electronic documents. It analyzes the possibility to use maximum information about internal and external opportunities and threats, t. e. more attention is paid to the process approach, especially to inputs and outputs (process results). The main purpose of this management 
by processes consists in a reduction of risks. Formed tracking procedures of risk factors are evaluated, are developed of activities to reduce risks and prevent of their appearance. Small business enterprises especially keenly feel the change in external conditions, and this has a significant impact on their functioning and further development.

The second important feature of the fifth version consists in more pronounced responsibility of management for developing and implementation of quality management system. In previous versions of the standard a representative of the quality manual was present. In other words the general director in his order gave responsible to the official for the realization of all necessary measures for the development and implementation of QMS. A result turned that the top management shifted the responsibility to someone another, if not fully, then at least partially. Now it is excluded.

These circumstances are taken into account during development and implementation of quality management system in Limited Liability Company (LLC) "ZETA "CONTACT", which is a manufacturer and supplier of contact network details for railway electrification. The investigated small enterprise is constantly expanding its range of products, which is manufactured for the energy industry. The success factors of the company on the market of St. Petersburg are named the following:

1) extensive practical work experience (since 2006);

2) understanding the needs of customers;

3 ) well thought-out organization of work processes;

4) rapid response to customer requests [31].

In company, where general director has personal interest in the quality management system, QMS according to the new version (fifth) of ISO 9001-2015 standard is implemented since February 2016. Here the emphasis is made not so much on the development and introduction of QMS documentation, but rather on the real functioning of processes. Therefore, the enterprise standards are developed taking into account the already existing order of organizing and conducting all kinds of activities, not to break the existing system and to comply with all the requirements of standards or other normative and technical documents for manufactured products. Basically, the content of standard is aimed at ensuring that all processes are carried out in system, without leadership intervention and without the so-called "management in manual mode".

Several departments are usually involved in the realization of any standard. At the same time the responsible executor on standard, as well as process manager organizes the work on the given direction in general. In the framework of the standard implementation they have the authority to give instructions to other managers and specialists, who participate in this project.

Today, one year later, only about $15 \%$ of the documentation of the supposed quality management system (3 standards out of 18) was implemented. Let us call these standards.
1. STO "Standards of Organization. Requirements". Implemented in June 2016. Responsible executor representative of the general director on the quality.

2. STO QMS "Monitoring and measurement of product". Implemented in July 2016. Responsible executor - chief of the technical control department.

3. STO QMS "Keeping of materials and finished products. Loading and unloading operations". Implemented in August 2016. Responsible executor chief of the warehouse.

Carried out the self-assessment of the company by top-management showed that the activities of technical control department (TCD) and the warehouse is the weakest link in the chain of the product life cycle.

TCD performs quality control of the finished product, including control of operations, acceptance tests, periodic tests and typical tests of product quality. Development of the standard has streamlined all of these types of controls and has revealed their phased implementation, accompanied by the filling of the necessary documents proving the correctness and completeness of control (acts, protocols, test logs, etc.). The introduction of this standard in June 2016 has allowed, according to deputy general director, completely release top-management from the management of this process. Now the management of this process is entrusted to the chief of TCD who deal with it.

Activities of warehouse extends to keeping and loading and unloading operations when sending products to consumers. The main difficulties in the warehouse work before the introduction of the quality management system standard consisted in a rapid and accurate selection of materials and components for the production of finished products. Very often, this simple procedure had being dragged on an indefinite period due to the fact that none of the warehouse workers did not know exactly what and where was. So the chief of the warehouse and the storekeepers long enough had to look for the necessary materials and semi-finished products. Introduced in August 2016 standard of organization describes the step by step the whole procedure, which implies a certain technology of placing these materials in the warehouse and eliminates the possibility of their losing, and thus minimizes the search time. In addition, in the standard are laid down certain requirements to conditions of storage and transportation, that preclude damage to materials and finished products during the execution of these processes. All this, according to deputy general director, allowed the $50 \%$ reduction of the company's leadership participation time in this process for implement of "management in manual mode".

Thus, we can talk about the positive influence of QMS to productive activities of LLC "ZETA "CONTACT". We will add another indicators, which presented in a table 1 . The volume of recycled metal can be selected as an indicator of activities of warehouse and of technical control department. In the warehouse the storekeepers under the supervision of the warehouse chief must bring on charge this volume (on the number and assortment), put it on a warehouse, keep and issue 
the on requirement to production. The inspectors of TCD during implementation of standard "Monitoring and measurement of product" must subject all manufactured production to acceptance tests. Although they use the selective control, at which try to check out each batch, they perform sampling, test and fill all the necessary documents of the standard (acts, reports, journals, including in electronic form).

Table 1. Main indicators of industrial activity of a small enterprise in $2016^{*}$.

\begin{tabular}{|c|c|c|c|}
\hline $\begin{array}{c}\text { Quarter } \\
\mathbf{2 0 1 6}\end{array}$ & $\begin{array}{c}\text { The volume of } \\
\text { recycled } \\
\text { metal , t }\end{array}$ & $\begin{array}{c}\text { The } \\
\text { average } \\
\text { number of } \\
\text { staff } \\
\text { people, } \\
\text { person }\end{array}$ & $\begin{array}{c}\text { Labor } \\
\text { productivity, } \\
\text { tons / person }\end{array}$ \\
\hline 1 & 184.031 .6 & 46 & 4000.7 \\
\hline 2 & 268.387 .2 & 53.5 & 5016.6 \\
\hline 3 & 388.815 .8 & 61.5 & 6322.2 \\
\hline 4 & 380.427 .5 & 61 & 6236.5 \\
\hline \multicolumn{2}{|c|}{ * Authors took figures in LLC "ZETA "CONTACT" and on the }
\end{tabular}

basis of them performed necessary calculations

According to table 1, it is obvious 2-fold increase in production volumes in the $3 \mathrm{rd}$ and 4 th quarters compared to the first, which was accompanied by a set of new staff (15 people.). However, labor productivity still grew every quarter, reaching a maximum in the 3 rd quarter, in 4 th practically remained at the same level, that exceed by more than 1.5 times magnitude of the 1 st quarter.

Since the labor productivity refers to indicators of economic efficiency, to a certain extent as a result of the introduction of the three considered standards, we can say about it rise. At this stage, while has not yet implemented all of the standards, and period of validity of embedded standard is short (less half a year), it is impossible to fully assess the effectiveness of implemented QMS.

Continued implementation of standards has been suspended due to a sharp increase in orders and a large booting of staff. The general director, who was the initiator of the creation of a quality management system in the company, has postponed the introduction, because he did not want that such activities gained formal. In fact after the introduction of the standard each time it is necessary to conducting training with the employees, obtaining feedback from them, the organization of checks the implementation of the standard.

At present STO "Input quality control organization" and related with it STO "Order of the formulation on permit of derogation (the deviation)" and STO "Management of nonconforming product" are prepared for the introduction. Implementation of the quality management system in LLC "ZETA "CONTACT" continues.

\section{Conclusion}

Carried out analysis of quality management technologies in the industrial epoch and post-industrial era in the context of their influence on the production activities of a particular small enterprise allows make the following conclusions.

1. The unifying processes, which were implemented at the micro, meso and macro levels in the first half of the twentieth century, lead to a general enlargement of production, to forming of associations of enterprises and provided consumers industrial products in large volumes. These processes, certainly had a negative influence on their quality, that caused the appearance of marriage. As a result for reworking defective items or simply recycling them have been required significant additional costs. In these circumstances, naturally, appearance of the concept of total quality control (TQC), which enriched the theory of quality management by technologies of the production process quality control (statistical control of process / 7 instruments of quality control). It is still used by modern companies.

2. In the second half of the twentieth century the further development of created international diversified corporations, offered a variety of products and services, contributed to the increase attention to the human factor. It lies at the basis of the total quality management (TQM) concept, directed to the constant improvement of the quality, which depends on the top management of the company, his responsibility and interest in it, the involvement of staff in this process, his encouragement and motivation. It allowed the development the technology of quality management - the quality management system, which is certified for compliance with international standards ISO 9000. It created a competitive advantages to large companies on a market segments for satisfying demands of consumers. Thus, initially bearing a recommendatory character ISO 9000 in the world markets have become the main measurer or guarantee of ensuring of consumers by products / services of high quality.

3. Often when implementing QMS associations of enterprises are facing with serious financial problems and the need in additional staff for the development of business processes, so for them became cheaper to buy a certificate of conformity and does not to carry out the necessary reorganization in the company. In this situation the image / brand, formed in companies, together with information and communication technologies helps them to survive long enough period of time. About quality it does not have to speak.

4. According to the authors, existing is a problem with the development and implementation of quality management system in large companies includes the low responsibility of top management (often its absent) and the lack of understanding of the QMS influence on organizational performance. In fact in the bureaucratic structure the general director got used to delegate to his deputies its powers. This also is associated with a lack at the top-management of knowledge in this area and highly qualified specialists on QMS. The described practice of step by step implementation it on a real small enterprise is proof of that.

5. Investigation of influence QMS on the production activities of enterprise is carried on the example of a small firm - LLC "ZETA "CONTACT", which effectively works in St. Petersburg. A fundamental 
condition of the success the project of implementation ISO 9000 in the company is considered the interest and personal involvement of general director, who continually increases his qualifications, now is learning the MBA program. He found a qualified specialist on QMS, who develops the business processes in the desired sequence for the enterprise, constantly conducts training of staff the quality management technology, patiently explaining of its benefits.

After the introduction of standards in the TCD and in a warehouse the general director could free himself from the operative production problems, and he delegated authorities to his deputy and heads of the relevant departments. So he focused on strategic tasks, that resulted in a 2-fold increase of production volume and growth of labor productivity by 1.5 times during 2016 . The growth in orders accompanied by an increase in staff, $t$. e. capabilities for enlargement in the future of this business are created. It further will be built on scientific basis of quality management, by using it advanced technology.

\section{References}

1. N.G. Ivanova, Herald SPbGUTD. Economic, humanitarian and social sciences, 4, 3-10 (2016)

2. N.G. Ivanova, St. Petersburg branch of the Bobkov Russian Customs Academy. Scientists notes, 2(58), 1929 (2016)

3. N.G. Ivanova, The new economic reality, cluster initiatives and development of the industry (INPROM2016), 37-43 (2016)

4. O.P. Gludkin, N.M. Gorbunov, A.I. Gurov, Y.V. Zorin, Total Quality Management: a textbook for high schools (Hotline-Telecom, Moscow, 2001)

5. I.V. Badiaev, A.Y. Podoinitsyna, Algorithm of the enterprise quality management system implementation, Engineering - From Theory to Practice, 57, 124-128 (2016)

6. N.G. Ivanova, Economy and management in the conditions of the global competition: problems and prospects, 191-196 (2016)

7. Z.I. Lavrova, Quality management: training manual (SPbGEU Publishing house, St. Petersburg, 2015)

8. V.V. Okrepilov, Management Consulting, 6(90), 40-49 (2016)

9. Briefly about ISO. http:// www.iso.org/iso/ru/home/news_index/mediakit.htm.

10. P.A. Marques, P.M. Meyrelles, P.M. Saraiva, F.J. Frazão-Guerreiro, IEEE International Conference on Industrial Engineering and Engineering Management, 894-898 (2016)

11. C.-K. Chen, K. Anchecta, Y.-D. Lee, J.J. Dahlgaard, A stepwise ISO-Based TQM implementation approach using ISO 9001:2015, 7, 4, 65-75 (2016)

12. A. Masseli, IEEE International Conference on Industrial Engineering and Engineering Management, 194-198 (2016)
13. M. Galetto, F. Franceschini, L. Mastrogiacomo, International Journal of Quality and Reliability Management, 34, 2, 231-250 (2017)

14. S. Sumaedi, T. Rakhmawati, International Journal of Systems Assurance Engineering and Management, 8, 219-229 (2017)

15. S. Hensch, Meat Market, 39(48), 4 (2017)

16. Z.I. Lavrova, Collection of St. Petersburg International Economic Congress materials (SPEC-2015), 555-561 (2015)

17. D.A. Komarov, Problems of Modern Economics, 17, 193-196 (2014)

18. N.I. Usik, A.E. Belorukov, A.V. Vasilenok, Economics and Environmental Management, 4, 70-77 (2016)

19. E.V. Fedotov, I.I. Sorokolet, Problems of enterprise development: theory and practice: proceedings of the 15 th international scientific-practical conference (2016)

20. Step ten - quality and management: proceedings of the joint project BIG team and Expert magazine "7 notes of management". http//www.big.spb.ru.

21. M.M. Sharkova, Student: science, profession, life: materials of III Russian student conference with international part. Omsk railways state university, 216219 (2016)

22. The World Economic Forum: Global Competitiveness Ranking 2015-2016. http://gtmarket.ru/news/2015/09/30/7246

23. GCI Global Competitiveness Index 2016-2017. $\mathrm{http}$ ///reports.weforum.org/global-competitivenessindex/competitiveness-rankings, 2016.

24. M.P. Baryshnikov, E.R. Ladygina, Modeling and development of metal forming processes, 18, 301-304 (2012)

25. GOST R ISO 9000-2008. Quality management systems. Fundamentals and vocabulary (Standartinform, Moscow, 2009).

26. Z.I. Lavrova, Science. Future: technologies and projects: materials of the international scientificpractical conference of young scientists and specialists, 2, 216-219 (2012)

27. V.I. Gissin, Quality management (MarT Publishing Center, Rostov-upon-Don, 2003)

28. V.V. Okrepilov, Quality Management: textbook (Polytechnic University Publishing house, St. Petersburg, 2013)

29. GOST R ISO 9001-2015. Quality management systems. Requirements (Standartinform, Moscow, 2015)

30. Z.I. Lavrova, Problems of organizations management improving. Russia and St. Petersburg: economy and education in the XXI century (SPbGEU Publishing house, St. Petersburg, 2016)

31. www.zetakontakt.ru/about/ 